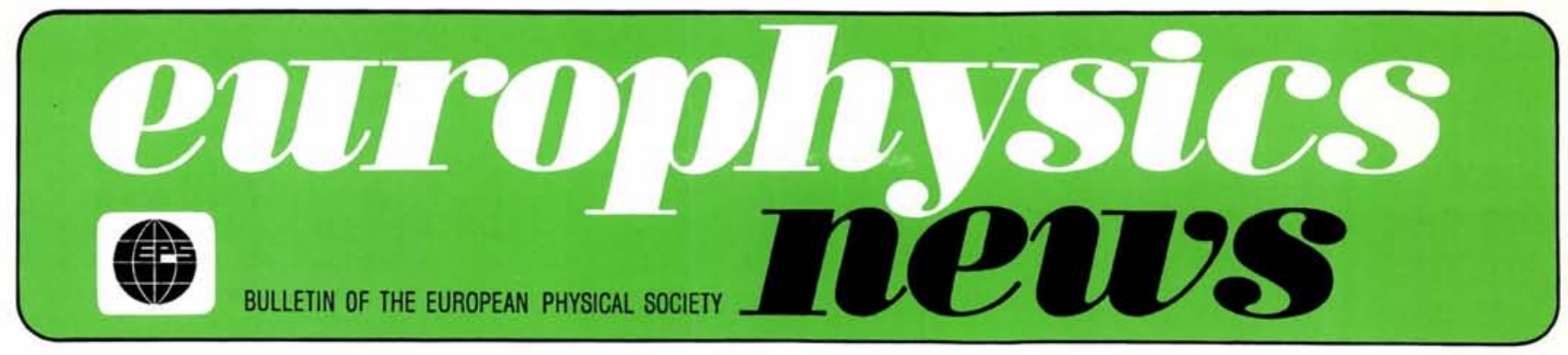

J.A.

The Dutch part of international Philips Research is housed in the "Natuurkundig Laboratorium", which, literally, means: "Physics Laboratory". Nomen est omen. Physics and physicists have, since the founding of Philips research in 1914 by the Leiden physicist Gilles Holst, played a crucial role in the growth and diversification of the Philips enterprise. Technical management contains many physicists and the top management of research has practically always been staffed by physicists. To obtain a better understanding of the situation, a brief historical survey of the development of Philips R \& D, is presented.

\section{Historical Background}

As early as the first decade of this century, the brothers Gerard and Anton Philips had come to the conclusion that if the company was to compete with manufacturers of incandescent lamps in the USA, then troubleshooting by engineers and chemists in the factory would not be enough; for a longer term policy they would need the support of scientific research. They took their time in finding the right man and in 1914 they found Dr. G. Holst willing to set up a team of promising scientists. The objective was, and still is, a fundamental understanding of the phenomena and materials that play a role in Philips products. Around a core of physicists Holst formed interdisciplinary teams that were problem-oriented, instead of product-oriented. It should be emphasized that at this time it was quite unusual

\title{
Physicists with Philips
}

\author{
G. Diemer, Eindhoven
}

(Recently retired from Philips Research Laboratories)

to employ physicists in private companies.

In accordance with its objective, the research became organisationally separate from the Philips factories, reporting directly to top management. A further aspect of Philips research introduced by Holst was that of stimulating, checking and maintaining its scientific level. Openness in communication with the scientific world has been made possible by having a smooth complementary system covering patent applications. Over the years, a capable organisation has been set up for the dissemination of research results both inside the Philips group and to a broader public. Good relations have been established with universities and a large number of our physicists have been named full-time or parttime university professors. Frequently doctorate degrees are obtained that are based on work in our laboratories.

\section{Organisation for Internationalisation} and Diversification

Even in the incandescent lamp period it was essential for the company to look beyond national boundaries if it was to achieve commercial growth. Research also contributed to diversification : X-ray equipment, radio valves and apparatus, gas discharge lamps, etc. After 1945, research and develop-

\section{Autumn Resolution}

Individual Ordinary Members are asked to verify without delay whether they have yet paid their subscription to the European Physical Society for 1979. A number of membership fees are still outstanding and Members are requested to check at once whether they are in arrears, so that the Society is spared costly reminder operations. Fees - of $28 \mathrm{Sw}$.Fr. for 4C Individual Ordinary Members (who are members of a member National Society) and of 112 Sw.Fr. for 4A members - should be credited to A/C No. 164899 at the Swiss Bank Corporation, CH - 1211 Geneva 11.

Europhysics News is published monthly by the European Physical Society. (c) 1979. Reproduction rights reserved. 


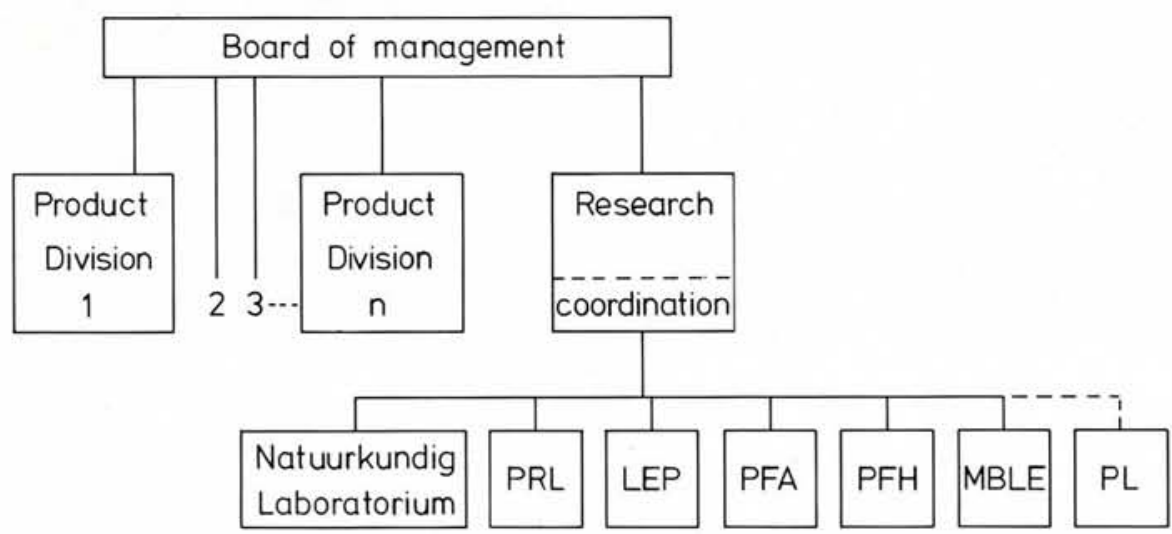

Organisational scheme of Philips product divisions and research. The research laboratories are located as follows: Natuurkundig Laboratorium in Eindhoven, the Netherlands; PRL in Redhill, England; LEP in Limeil-Brévannes, France; PFA in Aachen; PFH in Hamburg; MBLE in Brussels; PL in Briarcliff Manor, USA.

research programmes is left to the research laboratories themselves. Intensive horizontal personal contacts at the various levels make it possible to tune research to the long term needs of the Philips group. Internal mobility, resulting in a large number of scientists and engineers being found in the product divisions who have experience and good contacts with research, is important here, and the more so, in a period of manpower saturation.

The autonomy in the shaping of research programmes is reflected in the financing of research, the Board of Management deciding the total sum available. In recent years this has been about $1.1 \%$ of the total sales figure. This money is contributed by the various product divisions as a certain percentage of their turnover. The total budget devoted to research and development is about $6 \%$ of the total sales.

\section{Interdisciplinary Research Teams and Project Groups}

Within the research laboratories, the groups still are, generally speaking, of an interdisciplinary nature. From the founding of the laboratory this interdisciplinary group structure has been maintained and has been, on the whole, a successful one. The subjects range from general physical and chemical research, mathematics and computer software to more application-oriented activities in the fields of semiconductors, electronics, electronic systems, mechanics, etc. Physicists play important roles in most of these groups.

In Philips' view, research and development are distinguished not so much by whether the work is theoretical or fundamental-oriented as against application-oriented, but by the nature of the final results. There are, also projects of a mixed type which, from the very start, reveal features of both research and development. In such

\section{Communications Policy}

To further the scientific openness mentioned earlier, contacts with the scientific world via the publication of papers, attendance at conferences and exchange visits with other research institutes are strongly encouraged by the research management. This "scientific window" is considered important for maintaining a research standard at world level. Thus, within Philips research, one has succeeded in combining the scientific ambition of the individual with the willingness to work in the interests of the company.

Three house journals are published by the research laboratories: Philips Technical. Review, Acta Electronica and Philips Journal of Research. Various product divisions and staff organisations have also their own house journal (e.g. Medicamundi, Science and Industry). However the large majority of scientific and technological papers are published via outside journals. In addition, items suitable for a research press release are selected by the research coordinator and after editing they are sent, in four languages, to professional journals or to daily newspapers.

It is often said that industrial enterprises are at present time undergoing a transition from technology push towards market pull. In recent years scientists within Philips have, more than before, felt the need and also found the opportunity to discuss amongst themselves matters of science, technology and society. They have also contributed to such discussions on a national and international level (e.g. within the EPS).

The above trend is particularly noticeable in the professional area that is of increasing importance to Philips. It has caused interest to be focused on strategic planning in the Philips group as a whole. Moreover, about 10 years ago a new group was set up within research to look at "future studies". It gives advice to the research management and reports on possible future developments in certain areas of society which are, or may become, relevant to Philips industrial activities.

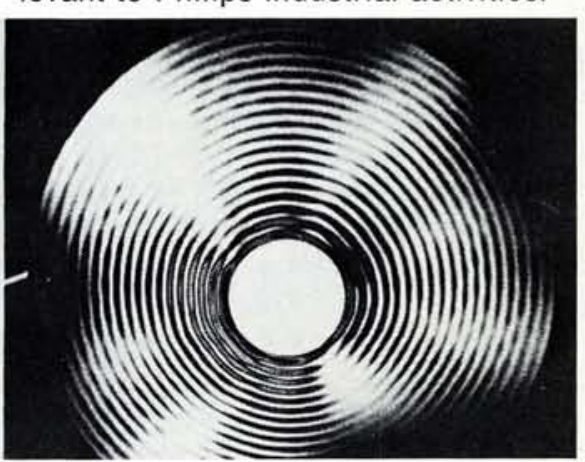

